\title{
Editorial
}

\section{Exploring the Arctic Ocean under Arctic amplification}

Ruibo Lei ${ }^{1}$, Zexun Wei ${ }^{2,3 *}$

${ }^{1}$ MNR Key Laboratory for Polar Science, Polar Research Institute of China, Shanghai 200136, China

${ }^{2}$ Key Laboratory of Marine Science and Numerical Modeling, First Institute of Oceanography, Ministry of Natural Resources, Qingdao 266061, China

${ }^{3}$ Laboratory for Regional Oceanography and Numerical Modeling, Pilot National Laboratory for Marine Science and Technology (Qingdao), Qingdao 266237, China

Received 15 July 2020; accepted 22 July 2020

๑) Chinese Society for Oceanography and Springer-Verlag GmbH Germany, part of Springer Nature 2020

Rate of surface air temperature increase in the Arctic is roughly twice that of the global average, and this phenomenon is referred to as "Arctic Amplification" (Serreze and Barry, 2011). The Arctic sea ice season (October to September) of 2017-2018 is the second warmest in Arctic since 1900 (Overland et al., 2018); 2014-2018 are the five warmest years in the Arctic since 1900 (Overland et al., 2018). Mean temperatures in Finland, Norway, and Svalbard in May 2018 are the highest in the instrumental record since the early 1900s (NOAA, 2018), and the extensive warm spells over Scandinavia led to extensive forest fires (Overland et al., 2018).

Arctic sea ice extent has decreased considerably mostly as a result of atmospheric and ocean warming. Sea ice decline is present in all months, and is the highest in September with a rate of $12.8 \%$ per decade since 1979 (Fetterer et al., 2017). The oldest ice, defined as ice that is more than 4 years old, is also normally the thickest ice. The percentage of the oldest ice in the March has reduced by $95 \%$ between 1985 and 2018 (Perovich et al., 2018). Thus, compared with 1979-2018 climatology, the Arctic Ocean in the ice season of 2017-2018 was dominated by much younger and thinner ice (Perovich et al., 2018). The oldest and thickest sea ice of the Arctic Ocean generally remains in the region between the Canadian Arctic Archipelago, Greenland, and the North Pole (Lindsay and Schweiger, 2015). Thus, the unprecedented polynyas that appeared in this region during winter 2017-2018 would promote further reduction of multi-year ice (Moore et al., 2018).

Artic sea ice reached an annual minimum extent of $4.59 \times 10^{6} \mathrm{~km}^{2}$ on 19 September 2018, which was the sixth lowest since satellite record began in 1979. Apart from Arctic Amplification, Arctic sea ice loss is driven by many complex radiative (e.g., Lee et al., 2017) and non-radiative forcings (e.g., Zhang, 2015), as well as internal variability (e.g., Ding et al., 2017; Kapsch et al., 2019). Projections from the latest generation of general circulation models indicate continued warming in the Arctic at higher rates than at lower latitudes, which would lead to further Arctic sea ice loss (Overland et al., 2014). With current $\mathrm{CO}_{2}$ emission rates, models project that Arctic sea ice extent would fall below $1 \times 10^{6} \mathrm{~km}^{2}$ within 20 to 25 years (SIMIP Community, 2020).

Arctic Amplification and sea ice reduction affect the climate, marine environments, and human society. Sea ice loss is a strong driver for primary production in the Arctic Ocean and its peripheral seas because of increased availability of light for photosynthesis (Barber et al., 2015). Primary production, involving mainly ice algae and phytoplankton, is the main energy source for the entire marine food web in the Arctic Ocean. Because of sea ice loss and ocean warming, multiple toxic harmful algal species have appeared in the Arctic food web at dangerous levels in recent decades (Natsuike et al., 2017). Landfast ice has been acting as a barrier protecting the coast from the erosive action of waves, and is shrinking in all dimensions throughout the Arctic (Lantuit and Pollard, 2008). Reduction in the extent and thickness of Arctic sea ice has allowed ships greater access to Arctic waters (Lei et al., 2015). Until now, sea ice has been the greatest obstacle to the use of Arctic sea routes by restricting the length of the operational season (Rogers et al., 2013). When warming in the Arctic is at a higher rate than that in lower latitudes, the north-south temperature difference is reduced. As a result, the jet stream slows down, favoring a more meandering north-south flow, and allowing warm air to penetrate farther north and cold air to plunge farther south (Francis et al., 2017).

The 9th Chinese National Arctic Research Expedition (CHINARE) took place between 20 July and 26 September 2018, and focused on change in Arctic sea ice and its response to climate change, as well as influence of sea ice on the environment and ecosystem in the Arctic region at various scales (Wei et al., 2019). Comprehensive multidisciplinary observations were conducted during the expedition, covering the fields of physical oceanography, atmospheric science, sea ice geophysics, marine chemistry, marine biology, geology, and geophysics in the regions of the Bering Sea, Chukchi Sea, Chukchi Plateau, Mendeleev Ridge, and Canada Basin. Measurement and sampling for oceanographic and sea ice studies were conducted at 88 marine and 10 ice stations. Some autonomous platforms, e.g., glider, unmanned ice station, and Ice-Tethered Profiler, were deployed to extend observations of the summer cruise into the winter. The 9th CHINARE was coordinated with a number of international polar research projects, including Multidisciplinary Drifting Observatory for the Study of Arctic Climate (MOSAiC) and the Year of Polar Prediction (YOPP). Some of the data acquired in situ during the 9th CHINARE will be integrated into these international projects. The papers published in this special issue are mainly based on, but not limited to, data obtained during this research expedition. There are also results of observations and analyses from previous CHINARE cruises or international research expeditions, as well as analyses of satellite remote sensing products and/or 
numerical models. They contribute towards advancing understanding of the current state or changes in the atmosphere, ocean, sea ice cover, and marine ecosystem in the Arctic.

Reduction in Arctic sea ice cover during summer reduces sea ice albedo resulting in more radiation being transmitted to the upper ocean. The ice-albedo feedback plays a key role in sea ice mass balance. Physical properties of snow, sea ice and melt ponds, as well as albedos of snow-covered ice and refreezing melt ponds were measured at ice stations during the 9th CHINARE. Cao et al. (2020) explore changes in the physical properties of snow and sea ice, and quantify the impact of the thin film of ice on the surface of refreezing melt ponds on albedo. Solar radiation absorbed by sea ice can result in interior melting of sea ice (Ehn et al., 2011). However, detailed information on vertical partitioning of solar radiation through the ice cover is very limited, because most measurements are made at the surface. A miniature near-infrared spectrometer was used in addition to the existing visible spectrometer to increase the spectral range of the spectrometry system. The performance of the near-infrared spectrometer was evaluated by integrating it into a fiber optic-based spectrometry system installed on an unmanned ice station. The system was used to measure vertical partitioning of solar irradiance through the ice cover during the 9th CHINARE (Nan et al., 2020).

There is high demand for subseasonal sea ice forecasts to support maritime navigation across the Arctic Ocean. Zhao et al. (2020) propose a bias correction method and apply it to outputs from two climate models to improve 2-month Arctic sea ice forecasts. Model results suggest that the proposed bias correction method improves forecasts, especially if large biases are present. The unprecedented polynya events that occurred north of Greenland during the ice season of 2017-2018 are important from the perspective of Arctic sea ice loss because they occurred in a region that could potentially be the last Arctic sea ice refuge in future summers. Lei et al. (2020) examine these polynya events in relation to atmospheric and ice conditions throughout the entire ice season. High resolution satellite images were used to determine spatial distributions of old thick ice, new thin ice, and open water during the polynya events. Sea ice surface temperature is an important Arctic climate parameter, and can indicate the presence of surface melt on summer sea ice. It can be considered as an integrator of surface energy fluxes. Ice surface temperature can be mapped at a basin scale using satellite infrared sensors under clear-sky conditions. An infrared radiometer onboard the R/V Xuelong was used to measure skin temperature during the CHINARE cruises. Data collected from six cruises are used to assess uncertainties in ice surface temperature products derived from measurements by satellite-borne thermal-infrared sensors (Li et al., 2020).

To support Arctic navigation with satellite data more effectively, sea ice concentration products derived from data collected by satellite-borne passive microwave sensors are compared with ship-based visual observations conducted during the CHINARE cruises (Xiu et al., 2020). A total of 3667 observations were made in the Arctic during five expeditions. Results reveal that floe size considerably influences estimates of ice concentration derived from passive microwave data. Most products underestimate sea ice concentration when small floes dominate. To extract multi-scale information from satellite sea ice concentration products, Zhang et al. (2020) conduct a successive corrections analysis using variational optimization. Applied to a two-dimensional sea ice concentration experiment with real observations from the Special Sensor Microwave/Imager product, this method propagates observational signals satisfactorily and excels in extracting multi-scale information. There is a consensus that interannual variability of sea ice is largely controlled by changes in atmospheric circulation regimes (Ogi et al., 2016). Using satellite-derived sea ice concentration data from 1979 to 2017, Liang et al. (2020) investigate the two leading principal modes of Arctic sea ice concentration variability in winter and summer, as well as their responses to atmospheric forcing.

With the rapid increased various applications in the Arctic in recent years, an increasing amount of ocean observation equipment, such as underwater unmanned vehicle, is being used to study the physical and biological processes of the Arctic Ocean below the ice cover (Lei et al., 2017). However, because the thick Arctic sea ice cover prevents underwater platforms from communicating with satellites, data transmission under sea ice makes use of acoustic communication. An improved least mean square/fourth direct adaptive equalizer has been developed for underwater acoustic communication in the Arctic ice zone. It is able to process complexvalued baseband signals, and its performance is verified using experimental data from the 9th CHINARE (Tian et al., 2020).

On the basis of the Redfield ratio (Redfield et al., 1963), nutrients can be used to trace the origin and transport of water masses, and to assess biogeochemical processes in the water column. A large amount of freshwater is stored in the western Arctic Ocean where nutrient dynamics are strongly influenced by the Beaufort Gyre (Zhuang et al., 2018). Several nutrient tracers are used to characterize water masses in the Canada Basin to better understand water mass structure and biogeochemical processes in the Arctic Ocean (Zhuang et al., 2020). The intensified hydrologic cycles throughout the Arctic have led to a decadal increase of discharge from Arctic rivers, which has further increased the fluxes of dissolved inorganic carbon (Tank et al., 2012) and organic matter (Lobbes et al., 2000) into the Arctic Ocean. Stable carbon and nitrogen isotopes provide important insights into the source and fate of organic matter in the ocean, and have been widely used to reveal changes in planktonic production and carbon cycle in the Arctic Ocean. Using seawater samples collected from the Chukchi and East Siberian seas and a three-endmember mixing model of C/N ratio and $\delta^{13} \mathrm{C}$ value, Jia et al. (2020) quantify the relative contribution of particulate organic matter from different sources. The principle of electrolytic concentration of tritium is to use the isotope fractionation of hydrogen isotopes in the gas and liquid phases. To achieve the target concentration, $\mathrm{H}_{2}$ and $\mathrm{O}_{2}$ are produced from direct catalytic electrolysis using a special solid polymer electrolyte (Nafion membrane). Lin et al. (2020) develop a method for the measurement of low-activity tritium in seawater, which can be used to determine tritium activity in the Arctic Ocean and provide accurate signals for quantifying water mass composition.

In the Arctic Ocean, net primary production has increased by approximately $30 \%$ over the past two decades (Ribeiro et al., 2017) largely because of sea ice retreat. To date, there has been little focus on studying the relationships between variations in summer sea surface temperature, sea ice extent and primary productivity in the Labrador Sea during the last millennium. To place changes in a long-term context and to better constrain future scenarios for this region, it is necessary to reconstruct these key parameters to determine their relationships on multi-decadal to millennial scales. To reconstruct marine productivity and climatic changes during the last millennium, Sha et al. (2020) analyze the biogenic silica content in sediment core GC4 from the Holsteinsborg Dyb, West 
Greenland, and reconstruct summer sea surface temperature using a diatom-based transfer function. Since the Mid-Pleistocene Transition, Arctic ice sheets have been sensitive to global climatic changes with an eccentricity period of $100 \mathrm{ka}$ (Condron and Winsor, 2012). Clay minerals deposited at the southern Mendeleev Ridge in the Arctic Ocean have a unique provenance, which can be used to reconstruct changes in the local sedimentary environment. Ye et al. (2020) reveal that high-frequency changes in clay minerals since the penultimate interglacial are recorded in sediments in core ARC7-E23 onbtained from the 9th CHINARE. Ice-rafted debris, clay minerals, and their grain sizes indicate the extent of the East Siberian ice sheet.

The main study area of CHINARE is the Pacific sector of Arctic Ocean. Since 1999, Chinese expeditions have been conducting investigation in this region; large amounts of valuable data and samples have been collected over the last two decades. With the launch and operation of the R/V Xuelong 2, an icebreaker of Polar Class 3, the CHINARE will explore the Arctic Ocean over larger spatial and temporal scales. Multidisciplinary investigations can be conducted in the multi-year ice zone. Study period will be extended and will begin in spring, when primary productivity peaks because of spring blooms, and end in autumn, when sea ice grows rapidly. Development of advanced autonomous observation equipment for ocean and sea ice observations will also further diversify the platform of CHINARE and effectively improve efficiency of in situ observations. This special issue systematically summarizes some, but not all, of the research results from the 9th CHINARE. Further analyses of data and samples, combined with numerical simulation experiments, and historical and other data from international partners will result in more in-depth syntheses.

\section{References}

Barber D G, Hop H, Mundy C J, et al. 2015. Selected physical, biological and biogeochemical implications of a rapidly changing Arctic Marginal Ice Zone. Progress in Oceanography, 139: 122-150, doi: 10.1016/j.pocean.2015.09.003

Cao Xiaowei, Lu Peng, Lei Ruibo, et al. 2020. Physical and optical characteristics of sea ice in the Pacific Arctic Sector during the summer of 2018. Acta Oceanologica Sinica, 39(9): 25-37, doi: 10.1007/s13131-020-1645-6

Condron A, Winsor P. 2012. Meltwater routing and the Younger Dryas. Proceedings of the National Academy of Sciences of the USA, 109(49): 19928-19933, doi: 10.1073/pnas.1207381109

Ding Qinghua, Schweiger A, L'Heureux M, et al. 2017. Influence of high-latitude atmospheric circulation changes on summertime Arctic sea ice. Nature Climate Change, 7(4): 289-295, doi: 10.1038/nclimate324

Ehn J K, Mundy C J, Barber D G, et al. 2011. Impact of horizontal spreading on light propagation in melt pond covered seasonal sea ice in the Canadian Arctic. Journal of Geophysical Research: Oceans, 116(C9): C00G02, doi: 10.1029/2010JC006908

Fetterer F, Knowles K, Meier W N, et al. 2017. Updated daily. Sea Ice Index, Version 3. Boulder, Colorado USA: National Snow and Ice Data Center, doi: 10.7265/N5K072F8

Francis J A, Vavrus S J, Cohen J. 2017. Amplified Arctic warming and mid-latitude weather: New perspectives on emerging connections. WIRS Climate Change, 8(5): e474, doi: 10.1002/wcc.474

Jia Renming, Mu Xinyue, Chen Min, et al. 2020. Sources of particulate organic matter in the Chukchi and Siberian shelves: clues from carbon and nitrogen isotopes. Acta Oceanologica Sinica, 39(9): 97-13, doi: 10.1007/s13131-020-1650-9

Kapsch M L, Skific N, Graversen R G, et al. 2019. Summers with low Arctic sea ice linked to persistence of spring atmospheric circulation patterns. Climate Dynamics, 52(3-4): 2497-2512, doi: 10.1007/s00382-018-4279-z

Lantuit H, Pollard W H. 2008. Fifty years of coastal erosion and retrogressive thaw slump activity on Herschel Island, southern Beaufort Sea, Yukon Territory, Canada. Geomorphology, 95(1-2): 84-102, doi: 10.1016/j.geomorph.2006.07.040

Lee S, Gong Tingting, Feldstein S B, et al. 2017. Revisiting the cause of the 1989-2009 Arctic surface warming using the surface energy budget: downward infrared radiation dominates the surface fluxes. Geophysical Research Letters, 44(20): 10654-10661, doi: 10.1002/2017GL075375

Lei Ruibo, Gui Dawei, Yuan Zhouli, et al. 2020. Characterization of the unprecedented polynya events north of Greenland in 2017/2018 using remote sensing and reanalysis data. Acta Oceanologica Sinica, 39(9): 5-17, doi: 10.1007/s13131-020-1643-8

Lei Ruibo, Tian-Kunze X, Li Bingrui, et al. 2017. Characterization of summer Arctic sea ice morphology in the $135^{\circ}-175^{\circ} \mathrm{W}$ sector using multiscale methods. Cold Regions Science and Technology, 133: 108-120, doi: 10.1016/j.coldregions.2016.10.009

Lei Ruibo, Xie Hongjie, Wang Jia, et al. 2015. Changes in sea ice conditions along the Arctic Northeast Passage from 1979 to 2012. Cold Regions Science and Technology, 119: 132-144, doi: 10.1016/j.coldregions.2015.08.004

Li Na, Li Bingrui, Lei Ruibo, et al. 2020. Comparison of summer Arctic sea ice surface temperatures from in situ and MODIS measurements. Acta Oceanologica Sinica, 39(9): 18-24, doi: 10.1007/s13131-020-1644-7

Liang Yu, Bi Haibo, Wang Yunhe, et al. 2020. Role of atmospheric factors in forcing Arctic sea ice variability. Acta Oceanologica Sinica, 39(9): 60-72, doi: 10.1007/s13131-020-1629-6

Lin Feng, Yu Tao, Yu Wen, et al. 2020. Electrolytic enrichment method for tritium determination in the Arctic Ocean using liquid scintillation counter. Acta Oceanologica Sinica, 39(9): 73-77, doi: 10.1007/s13131-020-1647-4

Lindsay R, Schweiger A. 2015. Arctic sea ice thickness loss determined using subsurface, aircraft, and satellite observations. The Cryosphere, 9(1): 269-283, doi: 10.5194/tc-9-269-2015

Lobbes J M, Fitznar H P, Kattner G. 2000. Biogeochemical characteristics of dissolved and particulate organic matter in Russian rivers entering the Arctic Ocean. Geochimica et Cosmochimica Acta, 64(17): 2973-2983, doi: 10.1016/S0016-7037(00)00409-9

Moore G W K, Schweiger A, Zhang J, et al. 2018. What caused the remarkable February 2018 North Greenland Polynya?. Geophysical Research Letters, 45(24): 13342-13350, doi: 10.1029/2018GL080902

Nan Liwen, Wang Xiaoping, Wang Hangzhou, et al. 2020. Feasibility study of miniature near-infrared spectrometer for the measurement of solar irradiance within Arctic snow-cover sea ice. Acta Oceanologica Sinica, 39(9): 115-124, doi: 10.1007/s13131-020-1632-y

Natsuike M, Matsuno K, Hirawake T, et al. 2017. Possible spreading of toxic Alexandrium tamarense blooms on the Chukchi Sea shelf with the inflow of Pacific summer water due to climatic warming. Harmful Algae, 61: 80-86, doi: 10.1016/j.hal.2016.11.019

NOAA. 2018. National Centers for Environmental Information, State of the Climate: Global Climate Report for May 2018. (2018-06) 
https://www.ncdc.noaa.gov/sotc/global/201805

Ogi M, Rysgaard S, Barber D G. 2016. Importance of combined winter and summer Arctic Oscillation (AO) on September sea ice extent. Environmental Research Letters, 11(3): 034019, doi: 10.1088/1748-9326/11/3/034019

Overland J E, Hanna E, Hanssen-Bauer I, et al. 2018. Surface air temperature in Arctic Report Card 2018. https://www.arctic.noaa.gov/ReportCard

Overland J E, Wang Muyin, Walsh J E, et al. 2014. Future arctic climate changes: Adaptation and mitigation time scales. Earths Future, 2(2): 68-74, doi: 10.1002/2013EF000162

Perovich D, Meier W, Tschudi M, et al. 2018. Sea ice in Arctic Report Card 2018. https://www.arctic.noaa.gov/Report-Card

Redfield A C, Ketchum B H, Richards F A. 1963. The influence of organisms on the composition of sea-water. In: Hill M N, ed. The Sea. New York: Wiley Interscience, 26-77

Ribeiro S, Sejr M K, Limoges A, et al. 2017. Sea ice and primary production proxies in surface sediments from a High Arctic Greenland fjord: Spatial distribution and implications for palaeoenvironmental studies. Ambio, 46(S1): 106-118, doi: 10.1007/s13280-016-0894-2

Rogers T S, Walsh J E, Rupp T S, et al. 2013. Future Arctic marine access: analysis and evaluation of observations, models, and projections of sea ice. The Cryosphere, 7(1): 321-332, doi: 10.5194/tc-7-321-2013

Serreze M C, Barry R G. 2011. Processes and impacts of Arctic amplification: a research synthesis. Global and Planetary Change, 77(1-2): 85-96, doi: 10.1016/j.gloplacha.2011.03.004

Sha Longbin, Li Dongling, Liu Yanguang, et al. 2020. Biogenic silica concentration as a marine primary productivity proxy in the Holsteinsborg Dyb, West Greenland, during the last millennium. Acta Oceanologica Sinica, 39(9): 78-85, doi: 10.1007/s13131-020-1648-3

SIMIP Community. 2020. Arctic sea ice in CMIP6. Geophysical Research Letters, 47(10): e2019GL086749, doi: 10.1029/2019GL086749

Tank S E, Raymond P A, Striegl R G, et al. 2012. A land-to-ocean perspective on the magnitude, source and implication of DIC flux from major Arctic rivers to the Arctic Ocean. Global Biochemical Cycles, 26(4): GB4018

Tian Yanan, Han Xiao, Yin Jingwei, et al. 2020. An improved least mean square/fourth direct adaptive equalizer for under-water acoustic communications in the Arctic. Acta Oceanologica Sinica, 39(9): 133-139, doi: 10.1007/s13131-020-1653-6

Wei Zexun, Chen Hongxia, Lei Ruibo, et al. 2019. Overview of the 9th Chinese National Arctic Research Expedition. Atmospheric and Oceanic Science Letters, 13(1): 1-7, doi: 10.1080/16742834.2020.1675137

Xiu Yuanren, Li Zhijun, Lei Ruibo, et al. 2020. Comparisons of passive microwave remote sensing sea ice concentrations with ship-based visual observations during the CHINARE Arctic summer cruises of 2010-2018. Acta Oceanologica Sinica, 39(9): 38-49, doi: 10.1007/s13131-0201646-50

Ye Liming, Yu Xiaoguo, Zhang Weiyan, et al. 2020. Ice sheet controls on fine-grained deposition at the southern Mendeleev Ridge since the penultimate interglacial. Acta Oceanologica Sinica, 39(9): 86-95, doi: 10.1007/s13131-020-1649-2

Zhang Rong. 2015. Mechanisms for low-frequency variability of summer arctic sea ice extent. Proceedings of the National Academy of Sciences of the United States of America, 112(15): 4570-4575, doi: 10.1073/pnas.1422296112

Zhang Xuefeng, Yang Lu, Fu Hongli, et al. 2020. A variational successive correctionsapproach for the sea ice concentration analysis. Acta Oceanologica Sinica, 39(9): 140-154, doi: 10.1007/s13131-020-1654-5

Zhao Jiechen, Shu Qi, Li Chunhua, et al. 2020. The role of bias correction on subseasonal prediction of Arctic sea ice during summer 2018. Acta Oceanologica Sinica, 39(9): 50-59, doi: 10.1007/s13131-020-1578-0

Zhuang Yanpei, Jin Haiyan, Chen Jianfang, et al. 2018. Nutrient and phytoplankton dynamics driven by the Beaufort Gyre in the western Arctic Ocean during the period 2008-2014. Deep Sea Research Part I: Oceanographic Research Papers, 137: 30-37, doi: 10.1016/j.dsr. 2018.05.002

Zhuang Yanpei, Li Hongliang, Jin Haiyan, et al. 2020. Vertical distribution of nutrient tracers in the western Arctic Ocean and its relationship to water structure and biogeochemical processes. Acta Oceanologica Sinica, 39(9): 109-114, doi: 10.1007/s13131-020-1651-8 